\title{
Fotografias Como um Recurso de Pesquisa em Marketing: o Uso de Métodos Visuais no Estudo de Organizações de Serviços
}

\author{
J. Ricardo C. de Mendonça \\ Maria de Lourdes de Azevedo Barbosa \\ André Falcão Durão
}

\section{Resumo}

Argumenta-se que a adoção de métodos visuais de coleta e análise de dados em pesquisas de marketing de serviços oferece riqueza de informações aos estudos na área, pois o uso de fotos (ou vídeos) pode proporcionar objetividade e credibilidade, na medida em que uma imagem fornece prova tangível da existência de determinado fenômeno. Para ilustrar o uso dos métodos visuais, foram selecionadas e analisadas fotos de um hospital e de um hotel, extraídas dos sites das empresas com o objetivo de verificar como o gerenciamento de impressões leva um hospital a usar estratégias para intencionalmente se parecer com um hotel. Para dar respaldo ao trabalho, utilizou-se como base teórica os métodos visuais na pesquisa, o papel do cenário nos encontros de serviços, o gerenciamento de impressões e o marketing de serviços. E, visando demonstrar a possibilidade de uso da metodologia em discussão, apesar das possíveis dificuldades da transposição dos métodos visuais, que são adotados na Sociologia e na Antropologia, acredita-se que a discussão metodológica e a ilustração do uso das técnicas de coleta e análise de dados irão contribuir para o enriquecimento do debate e para a busca do aprimoramento das ferramentas metodológicas em administração e, especificamente, em marketing.

Palavras-chave: pesquisa; métodos visuais; marketing de serviços; cenários de serviços.

\begin{abstract}
It is argued that the visual methods of data gathering and analysis in service marketing research yield a wealth of valuable information, as the use of pictures (or videos) imparts objectivity and credibility to the researchers' findings. In this article, pictures of a hospital and of a hotel were taken from their official web sites, and subsequently analyzed, to show how the recourse to impression management by both the hospital and the hotel has led the former to intentionally reproduce some features of the latter. The theoretical basis of the paper lies on the use of the visual methods; on the emphasis on the role of the scenery in service production, and on the literature on impression management and service marketing. In spite of the possible difficulties involved in the use of visual methods in marketing research, (and not only in Sociology and Anthropology, as is usually done), the contention is made that this article contributes to the enrichment of the debate, and for the quest for improvement of methodological tools in management and, specifically, marketing.
\end{abstract}

Key words: research; visual methods; service marketing; service set. 


\section{INTRODUÇÃO}

A administração, desde os seus primórdios, vem beneficiando-se de perspectivas e metodologias de outras áreas da ciência como, por exemplo, a sociologia, a antropologia, a ciência política, a psicologia. Entretanto várias abordagens e métodos dessas disciplinas permanecem desconhecidos ou pouco utilizados nos estudos em administração. Uma dentre essas abordagens utiliza os métodos visuais para coleta e análise de dados da vida social.

Os métodos visuais têm suas origens na Sociologia e na Antropologia. Harper (1988) coloca que a abordagem da Sociologia Visual contribuiu para muitos estudos nas décadas iniciais da sociologia americana, mas desapareceu e ressurgiu durante a década de sessenta. Para o autor "é justo dizer que de 1920 a 1960 não existiu Sociologia Visual" (p. 58).

Segundo Flick (2004), a discussão sobre uma sociologia visual, centrada em torno de fotografias e de filmes, é recente. Entretanto para a Antropologia a inclusão de fotos e filmes em estudos é mais significativa (Harper, 1988). Tanto é que Lindlof e Taylor (2002) chamam a atenção para o fato de que fotografias, filmes e vídeos têm sido utilizados como ferramentas comuns na coleta de dados na Antropologia há mais de 70 anos, o que é confirmado por Gagliardi (2002), quando coloca que a antropologia visual faz uso etnográfico do filme ou das fotografias para registrar, por meio de imagens, fenômenos culturais.

A abordagem visual é um enfoque metodológico em que o pesquisador ao estudar um fenômeno social, utiliza as imagens como fonte de dados, sejam elas estáticas (fotografias) ou em movimento (filmes e vídeos). Como método de pesquisa, a abordagem visual leva em consideração aspectos como a subjetividade do indivíduo que registra as imagens, bem como aquilo que ele escolheu incluir ou excluir da fotografia que foi capturada. Harper (1988) salienta o crescente reconhecimento do potencial dos métodos visuais para estudos tanto em laboratório, quanto em ambientes naturais (estudos de campo). Caulfield (1996) também ressalta o interesse dos cientistas sociais pelo método visual e a diversidade das imagens visuais. De acordo com Caulfield (1996, p. 56) os dois principais interesses da abordagem visual são "imagens produzidas pelo pesquisador (ou seus sujeitos) no curso de um estudo de campo (...) e imagens produzidas pelos atores sociais no contexto da vida cotidiana".

A capacidade da imagem fotográfica de conter a informação de maneira 
econômica e confiável torna possível uma catalogação mais eficiente de dados nas pesquisas. Porém os métodos visuais são pouco adotados nos estudos em administração e raramente têm sido usados em pesquisas qualitativas em marketing.

A pouca utilização do método nos estudos em administração pode ser constatada por meio da colocação de Gagliardi (2002, p. 128), que afirma: "O estudo dos artefatos e dos espaços coorporativos emergiu recentemente como uma das mais interessantes correntes dentro da abordagem geral das organizações entendidas como cultura". Seguindo essa perspectiva, o marketing de serviços, especificamente, pode valer-se do registro das evidências físicas para o envio de mensagens fortes que ajudam a estabelecer a imagem ${ }^{(1)}$ da empresa e a afetar as expectativas dos consumidores (Hutton \& Richardson, 1995).

Nesse caso, o cenário aparece como um dos elementos que influenciam a percepção do público em relação aos encontros de serviços, aspecto que é referendado por Hutton e Richardson (1995), quando apontam que os elementos tangíveis costumam ser citados pelos consumidores com muito mais freqüência do que os demais atributos determinantes da satisfação e da qualidade do serviço prestado.

A adoção de métodos visuais de coleta e análise de dados em pesquisas de marketing de serviços, bem como a inclusão das imagens coletadas nos resultados dos estudos oferece grande riqueza de informações, pois se acredita que pode proporcionar objetividade e credibilidade, na medida em que uma imagem fornece a prova tangível da existência de determinado fenômeno. Assim, neste ensaio, são abordados os métodos visuais, a importância do ambiente físico nos encontros de serviços e mostra-se um caso-exemplo de como se pode adotar este método na pesquisa de marketing. Para tanto são utilizadas quatro fotos (capturadas via internet), duas de um hospital e duas de um hotel, que retratam os mesmos espaços (apartamento e fachada) encontrados nos dois tipos de empresa.

\section{Os Métodos Visuais de Pesquisa}

A pesquisa qualitativa, onde se enquadram os métodos visuais, apesar de ser adotada de forma regular e legítima por sociólogos e antropólogos há várias décadas, só começou a ganhar espaço na área da administração a partir de 1970 (Godoy, 1995). O termo 'pesquisa qualitativa' é conceito amplo, que cobre várias formas de investigação, porém o pressuposto filosófico-chave é que todos os tipos de pesquisa qualitativa se baseiam em uma visão da realidade como 
socialmente construída pelos indivíduos em suas interações. Assim, as pesquisas qualitativas procuram entender e explicar o significado dos fenômenos sociais, causando o menor distúrbio possível no ambiente natural (Merriam, 1998).

Nesse sentido, Collier (1973) defende que o registro fotográfico contribui como fator de controle para a observação visual direta e acrescenta: "As fotografias são registros preciosos da realidade material" (p.7). Em complementação, Caulfield (1996) afirma que as imagens apresentam interesse sociológico pelo menos por três razões: 1) as imagens refletem o mundo vivo e as relações sociais entre os participantes; 2) fotografias são, freqüentemente, elementos formativos da vida social; e 3) as imagens podem reter informações documentais sobre os seus sujeitos.

Ao discutir as fotografias como instrumento e objeto de pesquisa, Flick (2004, p 161) destaca que "as fotografias, os filmes e o vídeo são cada vez mais utilizados como formas genuínas e fontes de dados". Porém vale ressaltar a discussão de Harper (1988) sobre as razões que levam a Sociologia Visual e os métodos visuais a serem discriminados por muitos pesquisadores. Conforme o autor, isso ocorre precisamente porque qualquer um pode tirar fotografias; "os métodos sociológicos, as pessoas tendem a acreditar, devem ser misteriosos e difíceis. (...) É inaceitável para muitos que algo tão simples possa ser útil como uma ferramenta sociológica" (Harper, 1988, p. 60).

Para Harper (1988) os sociólogos visuais sabem que tirar fotografias com importância teórica não é mais fácil do que realizar uma observação ou identificar variáveis significativas. Lindlof e Taylor (2002) afirmam que existem muitas características da mídia visual que apóiam o seu uso em pesquisas científicas. De acordo com Collier (1973), os seres humanos, por diversas razões, não são bons observadores. Assim, a grande capacidade de penetração da câmera fotográfica pode ajudar a ver mais e de forma mais acurada.

Com base em Flick (2004), algumas vantagens no uso de câmeras na pesquisa social podem ser apontadas: 1) as câmeras permitem registros (gravações) detalhados de fatos; 2) proporcionam apresentação mais abrangente e holística de estilos de vida e de condições sociais; 3 ) possibilitam o transporte de artefatos e a apresentação destes como retratos; 4) permitem a transgressão de limites de tempo e espaço; 5) podem capturar fatos e processos que sejam muito rápidos ou complexos para o olho humano; 6) permitem registros (gravações) não-reativas das observações; 7) são menos seletivas que as observações; e 8) as fotografias ficam à disposição de outras pessoas para serem reanalisadas.

Collier (1973, p. 6) destaca que a câmera é um instrumento; "ela documenta mecanicamente, mas a sua mecânica não limita, necessariamente, a sensibilidade 
do observador humano; ela é um instrumento que exige extrema seletividade". Para Duffield (1998), os métodos visuais de pesquisa têm potencial para cristalizarem dados e alcançarem audiências, de um modo que nenhum outro método pode, pois praticamente todos os aspectos da vida humana usam o sentido da visão, ou seja, a capacidade de ver. Apesar da maior credibilidade conferida às imagens, o seu significado é negociável e subjetivo. Harper (2000) ressalta que, apesar de as imagens representarem dados empíricos, elas não representam "a verdade", pois o próprio ato da observação escolhe um ponto de vista ${ }^{(2)}$.

Em pesquisas em que este método de coleta de dados é adotado, pode-se fazer uso de imagens preexistentes ou o pesquisador pode ele mesmo produzir as imagens que serão analisadas. Segundo Harper (1988) a Sociologia Visual apresenta várias abordagens, em que os pesquisadores fazem uso de fotografias para descrever ou analisar fenômenos sociais. Essas abordagens se subdividem em duas áreas principais: a) a primeira que utiliza a fotografia no sentido convencional de coleta de dados, sendo os métodos visuais normalmente adotados em trabalhos relacionados a um problema de pesquisa e a uma teoria específica; b) e a segunda, em que os sociólogos visuais utilizam fotos produzidas, ou seja, preexistentes na cultura estudada (Harper, 1988).

Harper (1988) descreve ainda, uma categorização de modos para a utilização de métodos visuais em pesquisas: o modo científico; o modo narrativo; o modo reflexivo; e o modo fenomenológico. No modo científico, as fotos podem ser usadas em pesquisas empíricas de várias formas. Diversas características de um fenômeno observável podem ser mais bem entendidas se "congeladas" em imagem fotográfica. As fotografias podem ser "lidas" no sentido de entender matizes da interação, da apresentação do self e as relações entre as pessoas e seu ambiente material. Além disso, como as imagens fotográficas isolam um momento no tempo, podem-se avaliar mudanças por meio de novas fotografias do mesmo fenômeno social ou de fenômeno similar. Ainda de acordo com Harper (1988), nas narrativas visuais ${ }^{(3)}$, que são utilizadas no modo narrativo da abordagem visual, as fotos estáticas assumem papel similar às narrativas etnográficas em filme ou de etnografias, que são construídas com base na vida social como ela naturalmente se desenvolve; já o modo reflexivo exibe uma relação diferente entre o pesquisador, a imagem e o sujeito da pesquisa. Nas palavras de Harper (1988, p. 65):

No método fotográfico reflexivo, o sujeito compartilha a definição dos significados; deste modo as definições são "refletidas de volta" ${ }^{(4)}$ " a partir do sujeito. Apesar disso ser difícil de fazer em uma pesquisa convencional, é mais fácil fazê-lo por meio de métodos fotográficos. O pesquisador pode começar da mesma maneira, ou seja, fotografando um sujeito ou um ambiente; mas 
então ele retorna ao sujeito para a definição do significado da imagem. Nesse processo, que tem sido chamada de "elicitação fotográfica"(5), os papéis do pesquisador e do sujeitos são alterados.

Por fim, o modo fenomenológico, sugere que fotografias podem expressar equivalência espiritual ou psicológica. Para Harper (1988, p. 66)

fotografias podem literalmente descrever, mas nos deixam imóveis; outras imagens podem inspirar nossas emoções, mas não ser úteis sociologicamente (ou até falsas). Algumas fotos, entretanto, fazem o oposto; ou seja, comunicam insights sociológicos de uma maneira artisticamente estimulante.

Segundo o autor a abordagem fenomenológica é, em essência, a elicitação do próprio conhecimento de alguém por meio da análise de fotografias que tenham significado pessoal.

Além dos aspectos mencionados, deve-se considerar também, ao se discutir atualmente o uso dos métodos visuais, a tecnologia digital. E para ilustrar as vantagens tecnológicas do uso das modernas câmeras digitais, Lindlof e Taylor (2002, p. 115) destacam que as máquinas fotográficas e câmeras de vídeo digitais apresentam vantagens em relação às máquinas fotográficas tradicionais, pois são extremamente compactas e leves; funcionam silenciosamente; fotografam em situações de baixa iluminação e não requerem processos caros; são facilmente carregadas em arquivos de computador, onde podem ser editadas e manipuladas das mais variadas formas, combinadas com outras mídias para colocação em sites na Web e eletronicamente compartilhadas com usuários distantes.

A ilustração da utilização do método visual neste artigo é composta por fotos de duas organizações, retiradas de sites na web - um Hospital e um Hotel - que são caracterizados por Zeithaml e Bitner (2003) como organizações de serviços interpessoais, em que o uso do cenário de serviço ocorre tanto por parte dos clientes, quanto por parte dos funcionários. Em ambos os tipos de organização, a complexidade do cenário de serviço é considerada elaborada. Nesse contexto, acredita-se ser necessária e apropriada uma maior discussão sobre o cenário de serviços para o atendimento do objetivo proposto neste ensaio.

\section{O Papel do Cenário nos Encontros de Serviços}

Um encontro de serviço é um período de tempo durante o qual os empregados e clientes de uma organização interagem diretamente (Lovelock \& Wright, 2001). Vale destacar que esta interação não se limita à dimensão interpessoal, mas engloba 
todos os aspectos da empresa com os quais o consumidor pode relacionar-se, incluindo, além do fator pessoal, as facilidades físicas e outros elementos visíveis (Grove \& Fisk, 1989).

Reafirmando que os encontros de serviços não se limitam às relações entre pessoas, Gagliardi (2002, p. 135) coloca que "em uma organização, fins são perseguidos, energias são investidas e idéias são concretizadas em máquinas, produtos e lugares". O autor evidencia ainda que nas organizações contemporâneas os espaços físicos estão vinculados a artefatos, pois as organizações, em geral, são receptivas aos recursos que possam melhorar a sua eficiência. Para alguns tipos de serviços, a evidência física ${ }^{(6)}$ ou o cenário é parte vital do sistema de prestação do serviço, porque, dentre todas as variáveis à disposição da organização, os elementos tangíveis do serviço são potencialmente aqueles que podem ser mais prontamente controlados pelos gestores (Hutton \& Richardson, 1995).

Ao discutirem as evidências físicas dos serviços, Zeithaml e Bitner (2003, p. 233) apontam que "os elementos genéricos de evidência física incluem todos os aspectos das instalações físicas da organização (cenários), bem como outras formas de comunicação tangíveis, quer sejam atributos exteriores quer sejam atributos interiores". Bitner (1992) apresenta contribuições importantes para a compreensão dos sistemas de prestação de serviços, explorando o conceito de Servicescape, que diz respeito aos ambientes sociais e físicos que envolvem experiência, transação ou evento de serviço. Inicialmente, o modelo Servicescape baseou-se exclusivamente na noção de ambiente físico. Contudo, considerandose que as pessoas em um ambiente podem influenciar as noções relacionadas ao espaço, o ambiente social foi inserido no modelo (Zeithaml \& Bitner, 2003). Analisando as dimensões ambientais do Servicescape, os fatores que constituem o ambiente físico referem-se às condições ambientais (temperatura, barulho, odor, música, dentre outros), espaço/funcionalidade (layout, equipamentos, mobília etc.) e sinais, símbolos e artefatos: sinalização interna, decoração, uniforme dos funcionários etc. Já os elementos do ambiente social envolvem as interações sociais que ocorrem entre funcionários da empresa, clientes e qualquer outra pessoa que esteja presente no mesmo ambiente físico. O conjunto de elementos ambientais irá determinar as respostas ou reações cognitivas, emocionais e físicas, tanto de clientes quanto de funcionários da empresa. Aqui, cabe destacar a noção de que as dimensões do ambiente de uma organização afetam tanto os comportamentos relacionados aos clientes, quanto aqueles relacionados aos funcionários da organização (Bitner, 1992).

Gagliardi (2002) aponta a importância do estudo dos artefatos para o estudo das organizações como sistemas de significados simbólicos. Segundo o autor, os artefatos, constituem fenômeno cultural primário que influencia a vida 
organizacional de duas formas: os artefatos tornam materialmente possível favorecer, obstruir ou mesmo prescrever a ação organizacional; e os artefatos, de forma mais geral, podem influenciar a percepção da realidade, chegando até a delinear crenças, normas e valores culturais. Além disso, "símbolos são concretizações dos sentidos e as coisas constituem seu domicílio mais usual e natural" (Gagliardi, 2002, p. 132).

O cenário de serviço afeta a percepção e o comportamento dos clientes e, conseqüentemente, sua satisfação e avaliação da qualidade; por isso é importante conhecer quais as características do ambiente de serviços que podem influenciar a percepção dos consumidores. Nesse sentido, Zeithaml e Bitner (2003) identificaram quatro tipos de papéis desempenhados pelos cenários de serviços: embalagem; facilitador; socializador; e diferenciador. A embalagem do cenário é aquilo que uma organização mostra para o exterior e, por isso, pode ser fundamental na formação das impressões ${ }^{(7)}$ iniciais ou para a construção das expectativas dos clientes (...)" (ênfase adicionada), fornecendo às organizações a oportunidade de transmitir determinada imagem para seu público-alvo por meio da configuração do cenário apresentado.

A forma como o cenário é projetado, segundo Zeithaml e Bitner (2003) (layout e arquitetura), pode ser um aspecto facilitador do processo de serviço e da interação do prestador de serviço como consumidor. Portanto o cenário deve ser planejado de acordo com o tipo de serviço a ser prestado e com as operações a serem executadas e podem ser melhorados quando o cenário de serviços é projetado com tal enfoque.

Nas palavras de Zeithaml e Bitner (2003, p. 237), “o projeto do cenário de serviços auxilia na socialização tanto de funcionários quanto de clientes, no sentido de que colabora para formar papéis, comportamentos e relacionamentos desejados". Os aspectos físicos do palco onde será desempenhado o serviço proporcionam 'pistas' para os atores envolvidos no encontro de serviço (funcionários e clientes) de como eles devem comportar-se nas interações.

Por fim, o cenário também pode ser caracterizado como tendo papel diferenciador para a organização de serviços, quando o seu projeto apresenta características distintas daquelas de seus concorrentes. Além disso, o cenário pode comunicar exatamente qual o segmento de mercado para o qual o serviço está direcionado, bem como para reposicionar a organização de serviços, buscando novos nichos de mercado (Zeithaml \& Bitner, 2003).

Berry (1981), Gronroos (1984) e Lovelock e Wright (2001) consideram tanto o contexto social quanto o contexto físico das trocas no serviço como aspectos fundamentais. Reforçando esse pensamento, Parasuraman, Zeithaml e Berry 
(1988) evidenciam que das 10 dimensões identificadas por eles como determinantes de qualidade de serviços, a maioria relaciona-se a aspectos ligados ao cenário social e ao cenário físico do serviço.

Os aspectos do cenário, quando bem gerenciados, podem potenciar todo o processo de serviço, agregando valores à sua execução, os quais afetarão de forma favorável o comportamento dos empregados e dos consumidores. Assim, acredita-se que os métodos visuais podem oferecer importantes insights para o estudo dos cenários em serviços.

Nesse artigo, serão considerados para a análise os elementos das instalações interiores e exteriores dos cenários de serviço, especificamente aqueles que podem comunicar aspectos do serviço por meio da observação dos dados visuais selecionados. Vergara, Carvalho e Gomes (2004, p. 16), ao discutirem a espacialidade do teatro das organizações, argumentam que: "nos palcos teatrais, o desenvolvimento de iluminação cenográfica consolidou o controle do olhar do espectador. Analogamente, nas organizações, as 'luzes' se acendem para a produção, canalizando a atenção do indivíduo para os resultados organizacionais".

Observa-se que, ao discutir as interações dos funcionários e seus clientes na organização de serviços como um teatro, parte-se para um enfoque dramatúrgico, que é aceito na literatura especializada em marketing de serviços. Essa perspectiva leva à discussão sobre a relação entre o gerenciamento de impressões (GI), o marketing de serviços e a metáfora dramatúrgica.

\section{O Gerenciamento de Impressões e o Marketing de Serviços}

Percebe-se crescente utilização, na literatura de marketing de serviços, da metáfora teatral, no sentido de entender e explicar os encontros de serviços. Um dos principais focos de análise da dramaturgia é como as pessoas criam e gerenciam impressões diante de uma audiência (Grove \& Fisk, 1989). A partir do enfoque de Goffman (1959), autores como Grove e Fisk (1989) e Grove, Fisk e Dorsch (1998) apontam que o teatro (os elementos da dramaturgia) passa a ser utilizado como ferramenta analítica para se estudarem os encontros de serviços. Sob esta perspectiva, os prestadores de serviços, como os atores em uma peça de teatro, apresentam elementos comuns no desempenho de seus papéis. Tanto atores, quanto os prestadores de serviços devem procurar criar e manter impressões ${ }^{(8)}$ favoráveis nas suas audiências, movimentando-se por cenário que é montado em palco, contando com ambiente de bastidores para lhes dar suporte e buscando, tal como o elenco de um espetáculo de teatro, o 'aplauso' (a satisfação) do seu público (Carvalho, 1998). 
A perspectiva de dramaturgia se baseia na visão do comportamento como metáfora dramática e retrata as interações sociais como teatrais, oferecendo o meio de analisar e descrever os comportamentos. Um dos principais focos de análise da dramaturgia é como as pessoas criam e gerenciam impressões diante de uma audiência (Grove \& Fisk, 1989).

Conforme Goffman (1959), o gerenciamento de impressões (GI) envolve a tentativa de estabelecer o significado ou o propósito de interações sociais, que dirigirão as ações das pessoas, ajudando a projetar as expectativas de papéis, ou seja, o que se espera de cada um.

De acordo com Alvesson (1990), o objetivo do 'gerenciamento da imagem' é produzir um 'retrato' (uma 'descrição'), com certo apelo, de uma organização para vários públicos - empregados, consumidores, acionistas, governo etc. - e posicioná-lo de um modo positivo. A imagem é escolhida por alguém dentro de um conceito específico, definindo alvo e significado para a ação, de forma a marcar o 'emissor' que tenta projetar determinada impressão para audiência (Alvesson, 1990). Mendonça (2003), de forma mais ampla, define o GI como todas as atividades que um ator social (indivíduo, grupo ou organização) desenvolve no sentido de influenciar o modo como outros o vêem, ou seja, a impressão ou a imagem que desenvolvem ao seu respeito.

O estudo do GI, de acordo com Ornstein (1989), tem se focado principalmente em comportamentos verbais; entretanto a exploração de comportamentos nãoverbais - tais como aqueles exibidos por meio da decoração de ambientes físicos - devem ser considerados. Grove, Fisk e Bitner (1992, como citado em Grove, Fisk, \& Dorsch, 1998), apresentam um modelo da experiência do serviço como drama, incorporando quatro componentes teatrais: (1) os atores, ou o pessoal do serviço cujos comportamentos e presença ajudam a determinar o serviço; (2) a audiência, ou os consumidores que são os receptores do serviço; (3) o cenário, ou o ambiente físico em que o serviço ocorre; e (4) a performance, ou a entrega do serviço.

Para Goffman (1959, p.15) a performance é "toda a atividade de um determinado participante, em uma dada ocasião, que serve para influenciar, de algum modo, quaisquer dos outros participantes". Conforme Gardner e Martinko (1988), no processo de gerenciamento de impressões, o ambiente proporciona o cenário e o contexto em que os atores realizarão suas performances para suas audiências. 


\section{Ilustração do Uso de Métodos Visuais no Estudo em Marketing de Serviços}

$\mathrm{Na}$ realização desta análise de imagem com o objetivo de identificar o seu significado dentro de uma representação social, precisou-se estar atento para as condições que permitiram a imagem representar o objeto, porque, antes de proceder à análise de uma foto, é necessário, verificar os vários sentidos que ela é capaz de propiciar.

Essas várias leituras, conhecidas como o caráter polissêmico da imagem, não caracteriza que uma foto possui vários sentidos, mas que seu sentido explícito cria classes de correspondências que permitem múltiplas interpretações. Essa característica é fruto da relação existente entre a imagem, o objeto e o observador. Assim é que se procurou o sentido e a interpretação dos pesquisadores envolvidos neste estudo, para verificar como o gerenciamento de impressões leva o hospital, intencionalmente, a se parecer com o hotel, investindo nos elementos físicos de seus cenários de serviços para criar apelo visual atrativo para os consumidores.

Considera-se neste trabalho que a fotografia é a interpretação de determinado recorte, sendo um relato da empresa sobre alguns cenários de serviços (apartamento e fachada) e fruto das representações de um indivíduo ou de um grupo.

Foram selecionadas para esse caso-exemplo duas fotos de hospital e duas de hotel, extraídas dos sites das empresas, que foram escolhidas por apresentarem similaridades de posicionamento de produto/serviço e por estarem na mesma categoria, considerada luxo ou 'cinco estrelas', estimando-se as duas como empresas do ramo da hospitalidade.

Para ilustrar os procedimentos adotados na análise de imagens paradas foram escolhidas fotos de dois cenários físicos comuns às duas empresas: apartamento (ambiente interno) e fachada (ambiente externo). A partir da análise das fotos, procurou-se verificar os aspectos comuns e diferenciados existentes nas imagens dos ambientes selecionados, tomando-se por base os itens constantes da Tabela 1 (4), e identificar em quais deles o hospital está teatralizando sua oferta de forma a se parecer com hotel. 
Tabela 1 (4): Critérios Adotados Para a Análise das Condições Ambientais

\begin{tabular}{lll}
\hline & \multicolumn{1}{c}{ CONDIÇõES AMBIENTAIS } \\
\hline \multicolumn{1}{c}{ Ambiente Interno } & \multicolumn{1}{c}{ Ambiente Externo } \\
\hline - Arquitetura interna e Decoração & - Arquitetura Externa \\
- Layout & - Cores \\
- Móveis e Equipamentos & - Sinais, Símbolos e Objetos \\
- Cores & - Paisagismo \\
- Sinais, Símbolos e Objetos & - Tamantrada \\
\hline
\end{tabular}

Fonte: baseado em Zeithaml e Bitner (2000), Hoffman e Bateson (2003).

A análise foi realizada por três avaliadores com perfis diferenciados para oferecer maior consistência aos dados. Um com experiência profissional na área de hospitalidade, outro especialista na área de organizações e um terceiro pesquisador da área de marketing.

O processo de análise constou de três etapas. 1) Primeira etapa: cada pesquisador, isoladamente, realizou a análise das fotos; 2) Segunda etapa: os três pesquisadores, em conjunto, estabeleceram comparações entre os elementos identificados por cada um deles na etapa anterior, formando o quadro básico que contemplou os aspectos comuns e diferenciados encontrados; 3) Terceira etapa: partiu-se para uma análise confirmatória das informações obtidas por meio das imagens, realizada de forma conjunta, a partir do quadro extraído da segunda etapa da análise, para verificar quais eram os elementos que permitiam identificar aspectos do cenário físico do hospital que possuíam uma identidade com os dos hotéis para, finalmente, levantar proposições sobre elementos do gerenciamento de impressões que vem sendo utilizado pelos hospitais como estratégia mercadológica para atrair e reter clientes.

\section{A Análise}

Grande parte da literatura recente tem analisado a mudança do eixo competitivo relacionado ao advento dos serviços agregados aos produtos e à melhoria da imagem da empresa na busca da criação de valor junto aos seus clientes. É nessa direção que os hospitais parecem estar redesenhando estratégias que vêm sendo empregadas para torná-los mais atrativos aos olhos dos clientes e do mercado. Uma das bases desse novo desenho indica uma ligação entre a gestão de saúde e a gestão hoteleira, resultando em um campo mais amplo denominado de 
hospitalidade. Assim sendo, um estudo comparativo entre imagens pareceu adequado e interessante para captar esses aspectos.

As fotos foram analisadas considerando-se as semelhanças com o seu referente, em que a imagem adquire uma relação como o objeto de sua representação por meio dos diversos sentidos incorporados. Assim é que, para efeito do caso ilustrativo desenvolvido neste estudo, se optou por abordar a imagem no plano da representação (o que ela mostra), no plano de conteúdo (o que ela significa) e no plano do significante (a realidade exterior a que ela faz referência). Ou seja, buscou-se com este caso-exemplo identificar as semelhanças ou diferenças com a realidade exterior a que a imagem remete.

A tentativa de gerenciar impressões por meio do cenário nos hospitais, com a intenção de fazê-los parecer-se com hotéis, está em função das relações de serviços em um hospital ocorrerem nas fases que se desenvolve um tratamento médico, que incluem diversos relacionamentos entre setores e entre pessoas, caracterizando, principalmente, um contato pessoal de alta complexidade que inclui a relação paciente/médico, bem como do pessoal de enfermagem, fisioterapeutas, nutricionistas, psicólogos e outros funcionários, como porteiros e recepcionistas, até o pessoal de limpeza e higiene. Além desses aspectos, mais do que em qualquer outra organização, os funcionários de contato se defrontam com pessoas fragilizadas pela doença e em processo de regressão psicológica, bem como familiares sofridos e desgastados (Gonçalves, 1998).

$\mathrm{Na}$ tentativa de criar ambiente mais atrativo para gerenciar os efeitos negativos dos aspectos anteriormente citados, os hospitais estão buscando apoio na indústria hoteleira. Ou seja, algumas estratégias de gerenciamento de impressões começam a ser incorporadas aos serviços hospitalares. Tal estratégia mercadológica já vinha sendo empregada pelos hotéis, na medida em que sua função foi sempre a de vender 'sonhos' e 'experiências agradáveis'.

Feitas essas ressalvas, cada um, dentre os critérios estabelecidos na Tabela 1 (4), mereceu algumas considerações, de modo que a análise levou aos seguintes resultados.

\section{Ambiente Interno}

São analisados neste tópico os ambientes internos das organizações (conforme as Figuras 1.4 e 2.4) e de acordo com quadro de referência constante na Tabela 1.4 e a teoria que dá suporte a este estudo. 


\section{Apartamento}

\section{Figura 1(4): Quarto do Hospital - http://www.hospitalaleinstein.com.br}

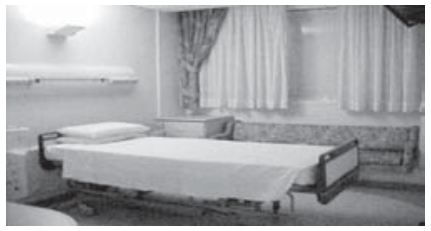

Figura 2(4): Quarto do Hotel - http://www.novotel.com.br

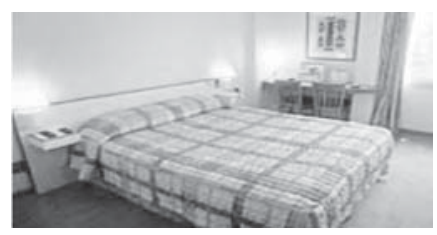

Arquitetura Interna: Apartamento

Os aspectos relacionados à arquitetura interna do apartamento permitem ao cliente comparar o que é ofertado pelas empresas. Na medida em que a competição aumenta em uma determinada área do setor de serviços, oportunidades para diferenciar a empresa tornam-se cada vez mais difíceis de encontrar (Bateson \& Hoffman, 2001). A evidência física e o tratamento dado aos encontros de serviços podem exercer impacto direto sobre os consumidores, estabelecendo uma diferenciação no serviço prestado.

Verificando-se o apartamento do hospital, percebe-se uma transformação de sua concepção. Antes frios e brancos; hoje com cortinas coloridas para dar vida ao ambiente; as paredes em tons pastéis para dar tranqüilidade e sensação de aconchego, o que faz com que os apartamentos do hotel e do hospital sejam bastante semelhantes. Esse aspecto refere-se ao papel de embalagem do cenário, Zeithaml e Bitner (2003, p. 236), ou seja, o cenário de serviços (apartamento) é aquilo que o hospital e o hotel mostram para o exterior e, por isso, é fundamental na formação das impressões ${ }^{(9)}$ iniciais ou para a construção das expectativas dos clientes. Os elementos da evidência física do serviço permitem transmitir determinada imagem para seu público-alvo por meio da configuração do cenário apresentado.

Analisando a arquitetura interna dos apartamentos (do hospital e do hotel), observa-se um traço específico que caracteriza a diferença entre os serviços de 
saúde e os serviços hoteleiros, a cama hospitalar, que tem design específico para esse tipo de atendimento. Essa característica, entretanto, não impede que a aparência geral dos dois apartamentos seja semelhante, pois os espaços, as cores e o restante do mobiliário apresentam aspectos similares. Até mesmo as cortinas já estão sendo utilizadas em hospitais, o que constituía restrição comum em alguns deles por questões de higiene e saúde. Verifica-se então, uma aproximação entre os aspectos físicos do apartamento de hospital na direção do ambiente encontrado no quarto de hotel.

\section{Layout:Apartamento}

Em virtude de que os ambientes de serviços são constituídos para atender às necessidades e interesses específicos dos clientes, o layout do espaço tem importância fundamental. A relevância do layout das instalações é especialmente evidente nos cenários de serviços, o que pode influenciar a satisfação dos clientes, o desempenho da empresa e o comportamento de busca de alternativa pelo consumidor (Zeithaml \& Bitner, 2003). Exemplos nesse sentido são encontrados, no caso dos hotéis, em que investimentos em apartamentos para deficientes físicos ou estruturas específicas para clientes da terceira idade, enquanto os hospitais apresentam layout próprio para a movimentação de pacientes, médicos e enfermeiros, mas com respeito e valorização do aspecto estético e aparência geral do apartamento.

Existe um layout padrão nos apartamentos, em que os móveis (camas e acessórios) estão dispostos de modo a oferecer espaço amplo e adequado à categoria dos produtos/serviços ofertados, permitindo no hospital e no hotel uma boa circulação de pessoas amplitude e conforto, até mesmo no caso de haver acompanhante, em ambos os casos.

\section{Móveis e Equipamentos: Apartamento}

A evidência física é parte vital do sistema de prestação do serviço, tanto que Hutton e Richardson (1995) colocam que, dentre todas as variáveis à disposição da organização, os elementos tangíveis do serviço são potencialmente aqueles que podem ser mais prontamente controlados pelos gestores. Considerando-se também que os espaços físicos estão vinculados a artefatos nas organizações contemporâneas, essas são receptivas aos recursos que possam melhorar a sua eficiência (Gagliardi, 2002) e a escolha dos móveis e equipamentos, bem assim a sua disposição no ambiente podem influenciar o resultado dos serviços.

Os móveis guardam semelhanças na qualidade percebida das peças, design e 
tipo de material, harmonia da localização em função da necessidade de cada espaço e das cores, em combinação com o conjunto da decoração. As imagens transmitem bem-estar, conforto, requinte, beleza, harmonia de espaços e cores apropriadas, com a finalidade de tentar criar uma imagem de qualidade e cuidado com os clientes.

\section{Iluminação: Apartamento}

Comparando-se o espaço do teatro com o das organizações, verifica-se que no teatro a iluminação do cenário é capaz de controlar o olhar do espectador. $\mathrm{O}$ mesmo pode ocorrer nas organizações, cujas luzes podem ser trabalhadas a favor da produção do serviço, focando a atenção do consumidor para os resultados dos encontros de serviços (Vergara, Carvalho, \& Gomes, 2004).

Os apartamentos, ambos com iluminação direta e indireta, possuem finalidades específicas. No caso do hospital, o uso de iluminação indireta próxima à cama para possibilitar cuidados com o paciente durante a noite, sem o incômodo da luz direta. Para o hotel esse tipo de iluminação facilita a leitura individual ou alguma outra necessidade do hóspede. A composição da luz na montagem dos dois cenários é semelhante na concepção.

\section{Cores: Apartamento}

As cores, suas tonalidades e combinações geram reações emocionais e comportamentos, às vezes inesperados, afetando, por exemplo, o humor das pessoas (Zeithaml \& Bitner, 2003). No caso do apartamento do hospital, percebese uma transformação de concepção, com a inclusão de cortinas coloridas, para dar vida ao ambiente e as paredes em tons pastéis para dar tranqüilidade e sensação agradável, o que deve colaborar na recuperação do paciente. No caso do hotel, os tons claros nas paredes e detalhes de decoração com cores diferenciadas (quadros e colcha) parecem indicar harmonia e beleza.

Esse tipo de mudança caracteriza o que Thomas (2002) definiu como movimento holístico da saúde, que estabelece o importante papel do meio ambiente no processo terapêutico. Essa perspectiva leva a constatar a adoção, por algumas empresas de saúde, de conceitos trazidos da área de hotelaria.

\section{Sinais, Símbolos e Objetos: Apartamento}

O estudo dos artefatos é importante para as organizações como sistemas de significados simbólicos, pois estes constituem fenômeno cultural primário que 
influencia a vida organizacional de duas formas: tornam materialmente possível favorecer, obstruir ou mesmo prescrever a ação organizacional; e, de forma mais geral, podem influenciar a percepção da realidade, chegando até a delinear crenças, normas e valores culturais. Além disso, "símbolos são concretizações dos sentidos e as coisas constituem seu domicílio mais usual e natural" (Gagliardi, 2002, p. 132).

Nesse sentido, os sinais expostos no interior de uma estrutura funcionam como comunicador explícito. Podem ser usados como etiquetas (ex. nome da empresa, nome do departamento), para orientação (ex. saída, entrada, toilletes) e para comunicar as regras de comportamento (ex. não fumar, silêncio). Entretanto os símbolos e objetos do ambiente também têm papel fundamental para os usuários dos serviços de saúde e de hotelaria, pois fornecem indicativos explícitos aos usuários acerca do significado do local e as normas e expectativas sobre o comportamento nesse local. Materiais de qualidade usados na construção, obras de arte, tapetes e certificados expostos podem comunicar significados simbólicos e criar uma impressão estética genérica (Zeithaml \& Bitner, 2003), o que pode ser constatado nas fotos analisadas.

\section{Ambiente Externo}

Figura 3(4): Fachada do Hospital - http://www.hospitalaleinstein.com.br

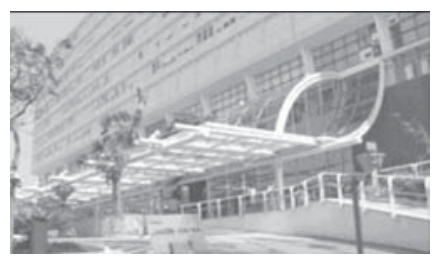

Figura 4(4): Fachada do Hotel - http://www.novotel.com.br

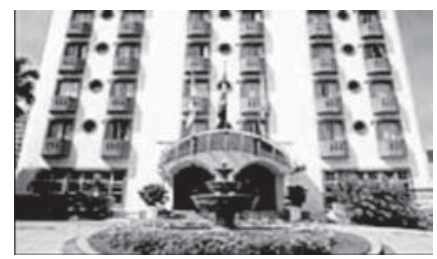

\section{Arquitetura Externa: Fachada}

O desafio de muitas empresas no momento de ofertar serviços é o de planejar o espaço e a evidência física, de modo que possam sustentar as necessidades e 
preferências do consumidor. Por meio da aparência externa de um prédio, por exemplo, o cliente pode avaliar o posicionamento da empresa, o tipo de serviço e o valor a ser pago pelo que é ofertado.

O cenário é aquilo que uma organização mostra para o exterior e, por isso, pode ser fundamental nas impressões iniciais ou para a construção das expectativas dos clientes - trata-se de uma metáfora visual para um serviço intangível. Uma instalação bem projetada ou mal projetada do ponto de vista do cliente pode ser uma experiência prazerosa ou não (Zeithaml \& Bitner, 2003).

Os dois prédios apresentam similaridades na sua estrutura, por terem características de modernidade, materiais com novas tecnologias de construção (vidros arredondados, pinturas especiais). Com formas arquitetônicas diferenciadas, mas elaboradas, ambos buscam transmitir idéia de organização, limpeza, beleza e sobriedade. Os prédios são imponentes e com traços elaborados, o que anteriormente constituía característica própria dos hotéis e está sendo adotada pelos hospitais para gerenciar impressões.

Vale salientar que cenários de serviços podem ser interpretados como forma de comunicação não-verbal da empresa, transmitindo, por meio sua características físicas, significados específicos (Zeithaml \& Bitner, 2003). Nesse caso, as fotos (3.4 e 4.4) transmitem imagens de locais sofisticados, podendo ser considerados como prédios de luxo e, se fosse realizada a análise das fotos das duas fachadas sem a identificação das empresas, provavelmente não seria possível ao observador distinguir qual, dentre elas, é efetivamente hospital ou hotel.

\section{Cores: Fachada}

As cores utilizadas nas fachadas dos dois prédios se assemelham pela tonalidade clara utilizada na pintura. Isto permite considerar que os matizes de cores utilizadas nas áreas externas do hospital, também observadas no hotel, buscam descaracterizar o aspecto mais austero, neutro e sem atrativos, que, ao longo dos tempos, foi sendo associado aos hospitais.

De acordo com os psicólogos ambientais, tanto cenários naturais quanto aqueles criados pelo homem ocasionam reações emocionais (Mintz, 1956; Maslow \& Mintz, 1956 como citado em Turley \& Milliman, 2000). Pode-se, portanto, argumentar que as cores utilizadas exercem função tão importante para a criação de imagem desses dois tipos de negócios quanto a estrutura e o estilo arquitetônico dos edifícios. 


\section{Sinais, Símbolos e Objetos: Fachada}

Em determinado ambiente, os símbolos, sinais e objetos podem transmitir significados de forma direta ou indireta aos clientes, sendo aspectos fundamentais na formação das impressões sobre o serviço. Esses critérios fornecem comunicadores explícitos, como a entrada de um local, que tem o propósito de orientar o cliente no ambiente a que se dirige. Oferecem também indicativos implícitos relacionados à qualidade do material utilizado na construção das instalações, as cores, os móveis e o layout que transmitem mensagens que agregam valor na percepção dos clientes acerca do serviço que estão comprando (Zeithaml \& Bitner, 2003).

As características arquitetônicas dos dois prédios propiciam sinais de organização, manutenção eficiente, higiene, cuidados com a aparência e com os jardins, verificando-se claramente a relação entre a embalagem para o produto e o cenário externo para os serviços, pois as características relacionadas aos símbolos, sinais e objetos permitem ao cliente formar pela imagem da "parte de fora" o que deve estar dentro da empresa (Zeithaml \& Bitner, 2003). Vale destacar que não se observou a existência de diferenças extremas entre os cenários analisados, ratificando a utilização de elementos do gerenciamento de impressões.

\section{Paisagismo: Fachada}

Com base em Edwards e Shackley (1992), pode-se argumentar que os jardins externos, comunicam significados simbólicos e criam impressão estética genérica da empresa Pelas fotos verifica-se que o hotel e o hospital realizaram investimentos semelhantes no aspecto paisagístico, criando harmonia entre a estrutura dos prédios e espaços disponíveis, oferecendo aspecto mais humanizado ao ambiente.

\section{Entrada: Fachada}

As entradas do hospital e do hotel apresentam similaridades quanto à aparência e forma, pois possibilitam uma visualização e identificação clara de sua utilidade, o que é fator importante, tanto para o acesso de pacientes como de hóspedes. As duas entradas sociais principais apresentam traços de arquitetura diferentes, mas não demonstram divergências aparentes quanto ao seu uso, o que pode levar o cliente a avaliar a fachada do hospital como a de um hotel, criando expectativas positivas sobre a empresa. 


\section{Tamanho do Prédio: Fachada}

Os clientes freqüentemente procuram indicadores do ambiente que os auxiliem a qualificar o local para, então, formar suas expectativas sobre a qualidade do serviço (Sharma \& Stafford, 2000). Um destes indicadores é o tamanho do prédio, que fornece sinais de imponência, segurança, status, consolidação da empresa no mercado, dentre outros.

Completada a análise, algumas considerações finais e proposições merecem ser feitas em relação ao tema proposto neste estudo, visando colaborar com futuros trabalhos voltados para a utilização dos métodos visuais na pesquisa em administração.

\section{Proposições Extraídas a Partir da Análise das Imagens}

Como resultado das análises realizadas, pôde-se chegar a algumas proposições relativas à questão da utilização do gerenciamento de impressões a partir dos cenários de serviços, como estratégia mercadológica para atrair e reter clientes. a) P1 Nas áreas comuns aos hospitais e restaurantes (apartamento e fachada) não se percebe diferenças marcantes na sua estrutura física e decoração. b) P2 Os hospitais estão utilizando ferramentas do gerenciamento de impressões para se tornarem mais parecidos com os hotéis aos olhos do cliente. c) P3 O investimento na estrutura física e decoração dos hospitais leva o consumidor a criar uma imagem mais positiva dos serviços de saúde. d) P4 O cenário de serviços é ferramenta importante para utilização pelos hospitais, como forma de oferecer aos clientes informações que lhe permitem fazer inferências sobre a qualidade do que é ofertado. e) P5 O cenário de serviços pode ser utilizado como estratégia de diferenciação entre as empresas de serviços de saúde.

As proposições extraídas desta análise se caracterizam como insights para o aprofundamento de pesquisas na área de marketing de serviços e para maior utilização dos métodos visuais em estudos dessa natureza.

Feitas essas colocações, parte-se para algumas considerações finais do trabalho mais voltadas para a utilização dos métodos visuais na pesquisa em administração. 


\section{Considerações Finais}

As imagens analisadas permitiram verificar as similaridades e as divergências existentes entre dois ambientes de duas empresas de serviços, bem como extrair sinais e informações em quantidade e qualidade suficientes para chegar-se às proposições constantes neste trabalho.

Essas proposições podem vir a contribuir para o entendimento relativo às mensagens que os cenários físicos transmitem, como proposição das empresas, e influenciam as imagens que são formadas pelos consumidores de serviços, principalmente levando-se em conta que as empresas empregam, nas suas mensagens visuais, táticas relativas ao gerenciamento de impressões.

Isso demonstra que a utilização dos métodos visuais como forma de coleta e interpretação de dados, na pesquisa de administração, pode contribuir para o aprofundamento de questões relacionadas ao marketing de serviços, pois as organizações constituem sistemas de significados simbólicos e os seus artefatos acabam por influenciar as ações organizacionais e a percepção da realidade (Gagliardi, 2002).

A concretização dos sentidos pode dar-se por meio da análise de imagens, considerando-se que todos os aspectos da vida humana usam o sentido da visão (Duffield, 1998) e, neste estudo, essa concretização ocorreu com a avaliação de fotografias dos cenários de duas empresas de serviços. As informações foram coletadas a partir de imagens estáticas que constituíram dados empíricos passíveis de seleção e interpretação, visto que o cenário, enquanto aspecto tangível do encontro de serviço, solicita profunda análise visual, já que exerce grande influência na percepção do cliente, pois a fotografia é considerada como registro precioso da realidade material (Collier, 1973).

Nesse sentido, as empresas estão permanentemente tentando "gerenciar imagens" e produzir "retratos", com alguns apelos aos seus vários públicos, para posicionarse de modo positivo (Alvesson, 1990) e, portanto, comportamentos não verbais, como a decoração de ambiente, são fundamentais para alcançar esse objetivo.

Com esse intuito, o marketing de serviços utiliza-se da metáfora teatral para entender e explicar os encontros de serviços, procurando verificar como as empresas criam e gerenciam impressões diante da audiência (Grove \& Fisk, 1989). O cenário físico ganha importância nesse contexto, e a observação das imagens desse ambiente tem papel importante no aprofundamento da teoria relacionada a esse tema, bem como pode permitir maior desenvolvimento de metodologias, como a empregada neste trabalho com o uso de imagens. 
Considerada como uma técnica de observação indireta da realidade social, o método visual, como qualquer outro método de coleta de dados, possui algumas limitações. Ao discutir o problema da observação e a natureza da fotografia, Collier (1973) aponta que uma das limitações da câmera são as próprias limitações de seu usuário. Ainda de acordo com o autor, enquanto os pesquisadores de campo não souberem o que fotografar, quando, quantas vezes e por que fotografar, a câmera não será vista como recurso funcional. Além disso, se os pesquisadores não dispuserem de recursos seguros para penetrar no conteúdo das fotografias, se não souberam o que é evidência de confiança e valor e o que é intangível e estritamente impressionístico, as fotografias não serão utilizadas de forma adequada.

Apesar das possíveis dificuldades da transposição dos métodos visuais adotados na Sociologia e na Antropologia, acredita-se que a discussão metodológica e a ilustração do uso de métodos visuais de coleta e análise de dados realizadas neste ensaio contribuíram para o enriquecimento do debate e para a busca do aprimoramento das ferramentas metodológicas em administração, especialmente na área de marketing de serviços.

Artigo recebido em 18.10.2004. Aprovado em 18.10.2005.

\section{NOTAS}

\footnotetext{
${ }^{1} \mathrm{O}$ termo imagem utilizado no contexto em que foi citado significa um conceito ou conjunto de opiniões subjetivas de um indivíduo, do público ou de um grupo social, a respeito de pessoa, produto, empresa etc.

${ }^{2}$ Para Collier (1973) as fotografias contêm um número suficiente de "verdades" não verbais, que permitem ao observador reconstruir a realidade esquemática e formar conceitos.

${ }^{3}$ Conforme Harper (2000, p. 724) "para expandir a idéia de dados empíricos de uma única imagem para uma sequiência de fotos, foi introduzido o conceito de narrativa visual".

${ }^{4}$ Da expressão original reflect back.

${ }^{5}$ Da expressão original photo elicitation.

${ }^{6}$ Características físicas que envolvem um serviço e ajudam os clientes a avaliar a prestação do serviço (Hoffman \& Bateson, 2003).

${ }^{7}$ A formação de impressões ocorre quando as pessoas descodificam as mensagens e formam impressões e imagens sobre outras pessoas.

${ }^{8}$ Idéia, sentimento ou opinião que o indivíduo tem sobre alguém ou algo, ou que alguém ou algo transmite ao indivíduo; pode ainda significar o efeito que uma experiência ou uma pessoa tem sobre alguém ou algo (baseado no Oxford-Advanced learner's dictionary, 2000).

${ }^{9}$ A formação de impressões ocorre quando as pessoas descodificam as mensagens e formam impressões e imagens sobre outras pessoas.
} 


\section{ReferênCIAS Bibliográficas}

Alvesson, M. (1990).

Organization: from substance to image. Organization Studies, 11(3), 373-394.

Bateson, J. G., \&

Hoffman, D. K. (2001).

Marketing de serviços (4a ed.).

Porto Alegre: Bookman.

Berry, L. L. (1981).

Perspectives on the retailing of services. In R. W. Stampfli \& E. C. Hirschman (Eds). Theory in retailing: traditional and nontraditional services. Chicago, IL: American Marketing Association.

Bitner, M. J. (1992).

Servicescape: the impact of physical surroundings on customers and employees, Journal of Marketing, 56(2), 57-71.

Carvalho, J. L. F. S. (1998).

A perspectiva dramatúrgica para marketing de serviços: uma visão interativa da comunicação empresarial. Dissertação de Mestrado. Pontifícia Universidade Católica do Rio de Janeiro, RJ, Brasil.

Caulfield, J. (1996).

Visual sociology and sociological vision, revisited. American Sociologist, 11(3), 56-68.

Collier, J. (1973).

Antropologia visual: a fotografia como método de pesquisa. São Paulo: EPU - Editora da USP.
Duffield, K. (1998).

Visual research methods. Recuperado em 15 março, 2004, de http//www. spinworks.demon.co.uk/pub/ visual.htm

Edwards, S., \&

Shackley, M. (1992)

Measuring effectiveness of retail window display as an element of the marketing mix. International Journal of Advertising, 11(3), 193-202.

Flick, U. (2004).

Uma introdução à pesquisa qualitativa (2a ed.). Porto Alegre: Bookman.

Gardner, W., \&

Martinko, M. (1988).

Impression Management in

Organizations. Journal of Management, 14(2), 321-338.

Gagliardi, P. (2002).

Explorando o lado estético da vida organizacional. In S. R. Clegg, C. Hardy, \& W. R. Nord (Orgs.). M. Caldas, R. Fachin, \& T. Fischer. (Orgs. versão brasileira). Handbook de estudos organizacionais: reflexões e novas direções (Vol. 2, pp. 127- 149). São Paulo: Atlas.

Godoy, A. S. (1995). Introdução à pesquisa qualitativa e suas possibilidades. Revista de Administração de Empresas, 35(2), 57-63.

Goffman, E. (1959).

The presentation of self in everyday life. Garden City, New York: Doubleday Anchor Books. 
Gonçalves, E. L. (1998).

Estrutura organizacional do hospital moderno. Revista de Administração de Empresas. 38(1), 80-90.

Grove, S. J., \&

Fisk, R. P. (1989).

Impression management in services marketing: a dramaturgical perspective. In R. A. Giacalone \& P. Rosenfeld (Eds). Impression management in the organization. Hillsdale, NJ: Lawrence Erlbaum Associates

Grove, S. J.,

Fisk, R., \&

Dorsch, M. J. (1998).

Assessing the theatrical components of the service encounter: a cluster analysis examination. The Service Industries, 18(3), 116-134.

Gronroos, C. (1984).

A service quality model and its marketing implications. European Journal of Marketing, 18(4), 36-44.

Harper, D. (1988).

Visual sociology: expanding sociological vision. American Sociologist, 19(1), 54-70.

Harper, R. H. R. (2000).

The organisation in ethnography: a discussion of ethnographic fieldwork programs in CSCW. Computer Supported Cooperative Work, 9(2), 239-264.

Hoffman, K. D., \&

Bateson, J. E. G. (2003).

Princípios de marketing de serviços: conceitos, estratégias e casos. São Paulo: Pioneira Thomson Learning.
Hutton, J. D., \&

Richardson, L. D. (1995).

Healthscape: the role of the facility and physical environment on consumer attitudes, satisfaction, quality, assessments and behaviors. Health Care Management Review, 20(2). 48-61.

Lindlof, T. R., \&

Taylor, B. C. (2002).

Qualitative communication research methods (2nd ed.). Thousand Oaks: SAGE.

Lovelock, C., \&

Wright, L. (2001).

Serviços, marketing e gestão. São Paulo: Saraiva.

Mendonça, J. R. C. (2003).

$\mathrm{O}$ estudo do gerenciamento de impressões nas organizações: uma visão geral do tema e considerações sobre a pesquisa e a produção no Brasil. In C. A. Carvalho \& M. M. F. Vieira (Orgs.) Organizações, cultura e desenvolvimento local: a agenda de pesquisa do Observatório da Realidade Organizacional (pp. 6190). Recife: EDUFEPE.

Merriam, S. B. (1998).

Qualitative research and case study applications in education (2nd ed). San Francisco: Jossey-Bass.

Mintz, S. W. (1956).

The role of the middleman in the internal distribution of a Caribbean peasant economy. Human Organization, 15(2), 18-23. 
Ornstein, S. (1989).

Impression management through office design. In R. A. Giacalone \& P. Rosenfeld (Eds.). Impression management in the organization. Hillsdale, NJ: Lawrence Erlbaum Associates.

Parasuraman, A.,

Zeithaml, V.A., \&

Berry, L. L. (1988).

SERVQUAL: a multiple-item scale for measuring consumer perceptions of service quality. Journal of Retailing, 64(1), 12-40.

Sharma, A., \&

Stafford, T. F. (2000).

The effect of retail atmosphere on customers' perceptions of salespeople and customer persuasion: an empirical investigation. Journal of Business Research, 49(2), 183-191.

Thomas, R. K. (2002).

Building on first impression. Marketing Health Services, 22(2), 3438.
Turley, L. W., \&

Milliman, R.E. (2000).

Atmospherics effects on shopping behavior: a review of the experimental evidence. Journal of Business Research, 49(2), 193-211.

Vergara, S. C.,

Carvalho, J. F., \&

Gomes, A. Z. (2004).

Controle e coerção: a pedagogia do olhar na espacialidade do teatro e das organizações. Revista de Administração de Empresas, 44(3), 10-19.

Zeithaml, V., \&

Bitner, M. J. (2000).

Services marketing - integrating customer focus across the fir (2a ed.). New York: Irwin McGraw-Hill.

Zeithaml, V., \&

Bitner, M. J. (2003).

Marketing de serviço: a empresa com foco no cliente (2a ed.). Porto Alegre: Bookman. 